\title{
Structure and Screech Tone of Radially Underexpanded Jet Emitted by Facing Cylinders
}

\author{
Hiromasa Suzuki', Koichi Kawasaki ${ }^{2}$, Masaki Endo², Yoko Sakakibara² \\ ${ }^{1}$ Tokyo Metropolitan College of Industrial Technology, Higashi-oi, Shinagawa, Tokyo, Japan \\ ${ }^{2}$ Tokyo Denki University, Ishizaka, Hatoyama, Hiki-gun, Saitama, Japan \\ Email:suzuki.h@metro-cit.ac.jp
}

How to cite this paper: Suzuki, H., Kawasaki, K., Endo, M. and Sakakibara, Y. (2020) Structure and Screech Tone of Radially Underexpanded Jet Emitted by Facing Cylinders. Open Journal of Fluid Dynamics, 10, 52-62. https://doi.org/10.4236/ojfd.2020.101004

Received: November 14, 2019

Accepted: March 2, 2020

Published: March 5, 2020

Copyright (c) 2020 by author(s) and Scientific Research Publishing Inc. This work is licensed under the Creative Commons Attribution International License (CC BY 4.0).

http://creativecommons.org/licenses/by/4.0/ (c) (i) Open Access

\begin{abstract}
An underexpanded jet has typical shock-cell structure and strongly oscillates, its behavior being known to cause many industrial problems. An underexpanded jet radially issues from intake and exhaust valves of an internal combustion engine, a pressure control valve and so on. When a supersonic jet exhausted from a circular nozzle impinges on a flat plate, the wall jet formed on the plate often becomes underexpanded and spreads out radially. Such underexpanded impinging jet is one of models of supersonic jets on laser cutting process and glass tempering process. In this study, an underexpanded jet radially discharged from a circular slit nozzle, which consists of two cylinders, was experimentally examined for different nozzle pressure ratios and for different diameters of cylinder. Jet structure was analyzed by means of a visualization e.g. Schlieren method. A noise emitted from the jet was measured and the frequency of screech tone was analyzed. The experimental results were compared with those of a two dimensional jet issuing from a rectangular nozzle. Furthermore, a comparison of visualized sound waves with the screech tone frequency reveals that the sound source measured was in the vicinity of the end of the second cell and that the length of the second or third cell was one of the most important parameters to determine the frequency of the emitted screech tone.
\end{abstract}

\section{Keywords}

Acoustic Noise, Underexpanded Jet, Visualization, Shock Wave

\section{Introduction}

The underexpanded radial jet occurs in a flow field around an intake valve in an internal combustion engine and a pressure regulating valve in a piping system. 
In addition, when an underexpanded jet from a circular nozzle or a rectangular nozzle impinges on a plate at a relatively short distance between the nozzle and the plate, the wall jet spreading radially on the flat plate may also be underexpanded [1]. Such a flow field is practically formed when an assist gas of a laser cutting machine or a quenching gas of tempered glass impinges on an object [2] [3] [4]. In this way, the underexpanded radial jet is a flow field occurring in many industries, and understanding the structure of the jet is very important from a viewpoint of engineering practice. Until now visualization experiments and numerical simulations of the underexpanded jet have been performed in order to grasp the structure of the jet. Numerical or experimental studies having been carried out so far by many researches reveal that the underexpanded jet issuing from a convergent nozzle emits a broadband noise at low frequency and a narrow-band noise at high frequency called screech. The frequency and the pressure level of the emitted noise have been analyzed, which is closely related to oscillation modes of the jet [5] [6] [7] [8] [9]. In addition, feedback mechanism that causes the screech to radiate has been studied [10]-[15]. However, many researchers devote themselves to researches relevant to an axisymmetric or rectangular free jet and a main jet of impinging jet. There has been little research on the characteristics of supersonic jets spreading on the wall after the jet impingement. The radial jet spreads like a disc, so that it is characterized by its width gradually narrowing in accordance with going downstream. Therefore, the cell length of the radial jet also decreases as it goes downstream. On the other hand, the cell length of the axisymmetric or rectangular jet does not decrease basically assuming that the flow is non-viscosity. Thus, the radial jet structure is different from that of axisymmetric or rectangular jet and the characteristics of acoustic noise generated in the flow field are also unique. The characteristics of broadband noise in radial jets were investigated by Y. Hiramoto et al. [16]. In this paper, in order to elucidate the influence of a typical structure of the radial jet on the characteristics of broadband noise, the underexpanded radial jet is visualized and the jet structure is analyzed. The paper shows that the length of the $1^{\text {st }}$ cell is closely related to the dominant frequency of the broadband noise and that the broadband noise is supposed to radiate from the end of the $1^{\text {st }}$ cell.

\section{Experimental System and Method Introduction}

The experimental apparatus in this Study is shown in Figure 1. The compressed air is dehumidified by the air dryer and passes through the surge tank to remove the pulsation of the air. Finally, the air is supplied to two high-pressure tanks in a soundproofed room. The pressures in two tanks are kept equal each other by the valves with the aid of the manometer. The excess air is discharged to the outside of the room through the silencer.

The ambient temperature and the air temperature in each high-pressure tank are ordinary temperature. Cylinders with inner diameter $D_{1}$ and outer diameter $D_{2}$ are attached to the high pressure tank. Those outlets are placed face to face 
each other with gaps $b=2 \mathrm{~mm}$ as shown in Figure 2. Two kinds of cylinders, i.e. a cylinder with $D_{1}=10 \mathrm{~mm}$ and $D_{2}=12 \mathrm{~mm}$ and a cylinder with $D_{1}=14 \mathrm{~mm}$ and outer diameter $D_{2}=16 \mathrm{~mm}$, are employed. The air supplied to the tank goes through the cylinder and its flow direction changes near the end of cylinder, and then the gap discharges the air into the atmosphere. The jet issuing from the gap spreads radially like a disc. The shape of the inner wall of the cylinder is designed and processed with a curved surface so as to reach the sonic speed at the exit, and its inner surface is well-finished. In this study, the small gap between two cylinders is called "slit nozzle".

Figure 3 shows the optical system of the Schlieren method using for visualization. A xenon flash is employed as a light source. The light emitted during 180 ns becomes parallel light rays through the condenser lenses, the pinhole and the 1 st collimator lens. After passing through the radial jet, the light is collected on the knife edge. Finally, a side view of the radial jet is photographed.

The sound measurement system of the flow field is shown in Figure 4. A sound emitted from the underexpanded jet has directivity, but it is known that the frequency of screech is small in angle dependency [6] [17]. The microphone

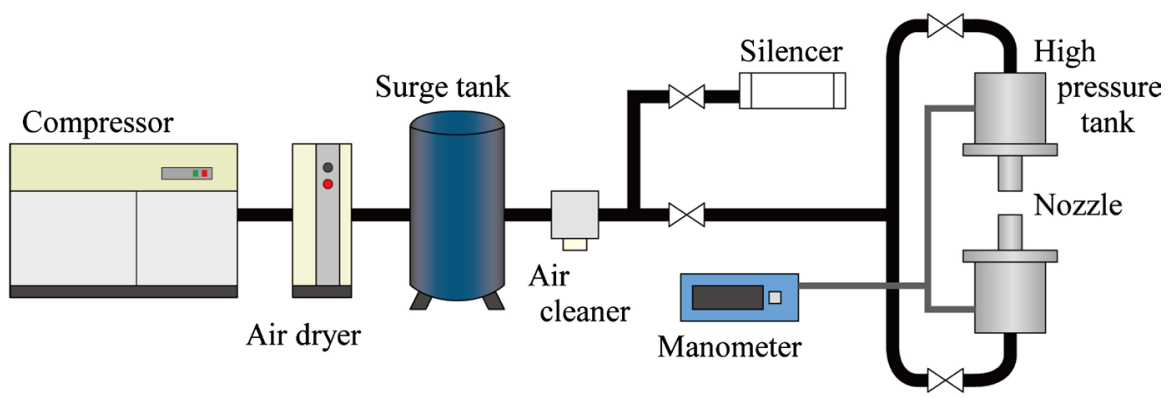

Figure 1. Experimental apparatus.

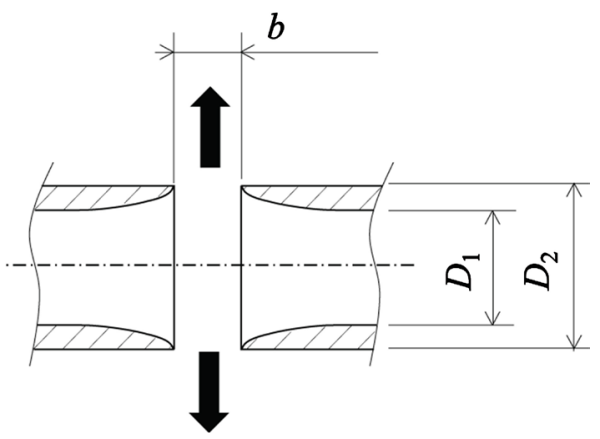

Figure 2. Geometries of nozzle.

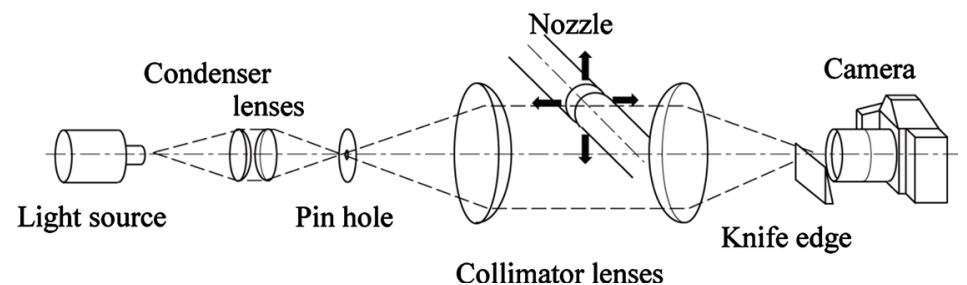

Figure 3. Optical system of the Schlieren method. 
is pointed at the slit nozzle at $45^{\circ}$ against the jet axis. The distance from the nozzle exit is $r=750 \mathrm{~mm}$. To prevent the jet noise from reflecting from the experimental setup, a sound insulation material is affixed on the nozzle outer wall other than the nozzle lip and the wall surface of the experiment equipment stand.

\section{Results and Discussion}

\subsection{Flow Visualization}

Figure 5 shows the pictures of radial jet with the nozzle outer diameter $D_{2}=12$ $\mathrm{mm}$, taken by Schlieren method using the optical system of Figure 3. The nozzle exit is located at the center of the upper part of the photograph. This is an image obtained by averaging 30 pictures taken randomly at each pressure ratio. The range of pressure ratio $p_{0} / p_{a}$ is from 2.00 to 4.00 , where $p_{0}$ is the stagnation pressure in the high-pressure tank and $p_{a}$ the atmospheric pressure. Since the knife edge is arranged horizontally so as to block the upper half with respect to the focusing light, an expansion region of the jet is taken in dark. At $p_{0} / p_{a}=2.00$ in Figure 5(a), the cell structure is not observed in the jet. The jet stream gradually narrows as going to the downstream side, and eventually the boundary becomes unclear and mixed with the surrounding atmosphere. At $p_{0} / p_{a}=2.25$ in

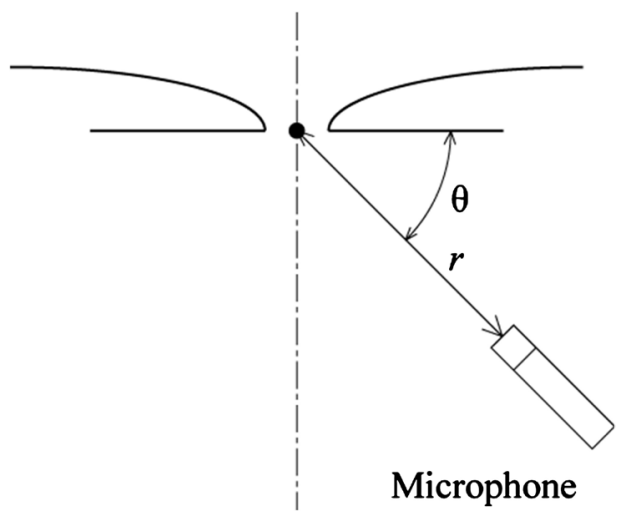

Figure 4. Sound measurement system.

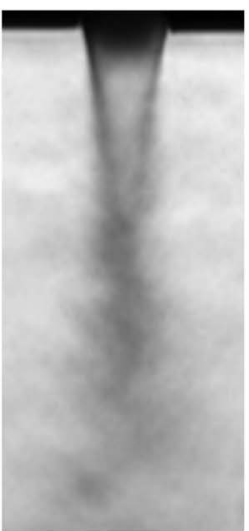

(a)

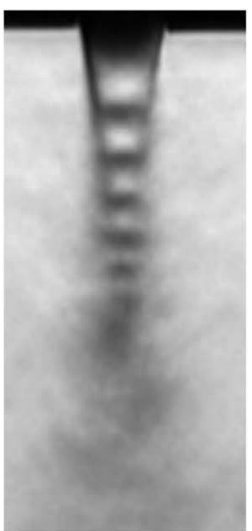

(b)

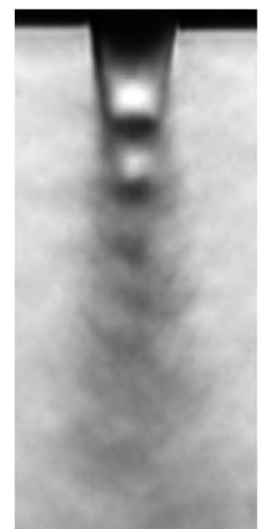

(c)

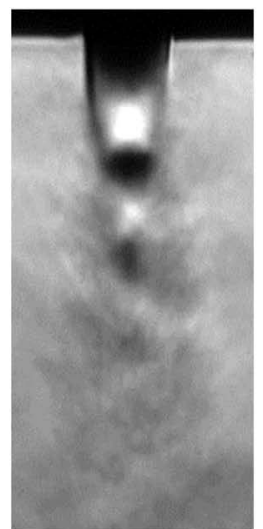

(d)

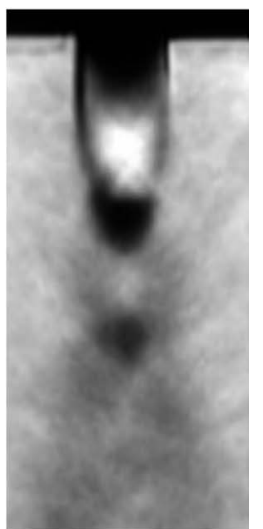

(e)

Figure 5. Schlieren image $\left(D_{2}=12 \mathrm{~mm}\right)$. (a) $p_{0} / p_{a}=2.00$; (b) $p_{0} / p_{a}=2.25$; (c) $p_{0} / p_{a}=2.50$; (d) $p_{0} / p_{a}$ $=3.00 ;(\mathrm{d}) p_{0} / p_{a}=4.00$. 
Figure 5(b), the cell structure appears in the jet and 6 cells may be counted. The number of countable cells is 4 at $p_{0} / p_{a}=2.50$ in Figure $5(\mathrm{c})$, and 3 at $p_{0} / p_{a}=3.00$ in Figure 5(d). $p_{0} / p_{a}=4.00$ or more, no significant change is observed in the cell structure.

\subsection{Cell Length and Location of Density Wave Source}

Figure 6 shows one of instantaneous images of Schlieren pictures randomly taken at $p_{0} / p_{a}=4.80$ with $D_{2}=12 \mathrm{~mm}$. Circular arcs are observed where the density change is comparatively sharp. These density changes are suggested to originate from the jet because these circular arcs seem to surround the jet and are concave shape with respect to the jet. Comparing many instantaneous images with each other shows that these density changes propagate to the outer side as if sound waves were emitted from the jet and that they are emitted alternately to the left and right sides. Such antisymmetric phenomena were reported in rectangular jets [7] [8] [9]. Therefore, these are density waves, which are considered to be comparative strong sound waves visualized by means of Schlieren method.

Figure 7 shows the cell lengths and the density wave generation location. Let the first cell length be $L_{1}$, the second cell length $L_{2}$, and the third cell length $L_{3}$.

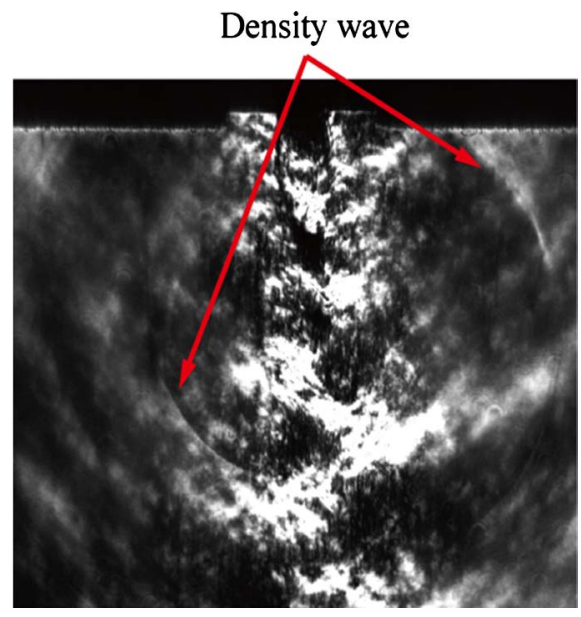

Figure 6. Density waves generated from jet.

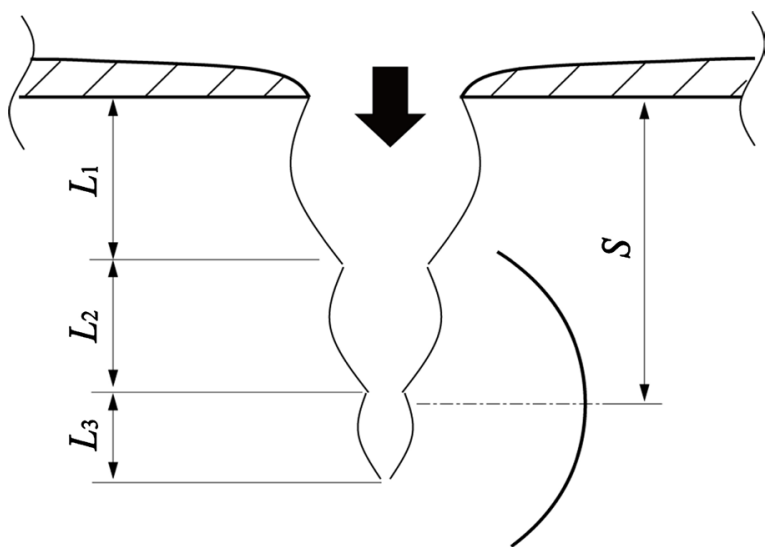

Figure 7. Cell lengths and the density wave generation location. 
These lengths are measured from the averaged image of Schlieren photograph. Additionally, the distance $S$ is measured between the tube wall and the farthest point from the jet axis where the density wave is reachable. The source of density wave is assumed to exist at $S$ downstream position in the jet. The location of density wave source is measured from the instantaneous Schlieren photograph as in Figure 6.

Figure 8 shows the cell nodes $\left(L_{1}, L_{1}+L_{2}, L_{1}+L_{2}+L_{3}\right)$ of the radial jet and the density-wave source $S$ with $D_{2}=12 \mathrm{~mm}$. The ordinate is the distance from the nozzle exit to these locations and the abscissa the pressure ratio. The density wave was not observed at the lower pressure ratio than 4.40 and the analysis ranging from 4.40 to 6.00 was carried out. As the pressure ratio increases, the first cell length and the second cell length increase, but the third cell length does not increase much. At the pressure ratio from 4.40 to 5.20 , the source of density wave is in the vicinity of the upstream side of the third cell. In the pressure ratio higher than that, the density wave source position moves to the downstream side as the pressure ratio increases. Figure 9 shows each cell lengths with $D_{2}=16 \mathrm{~mm}$.

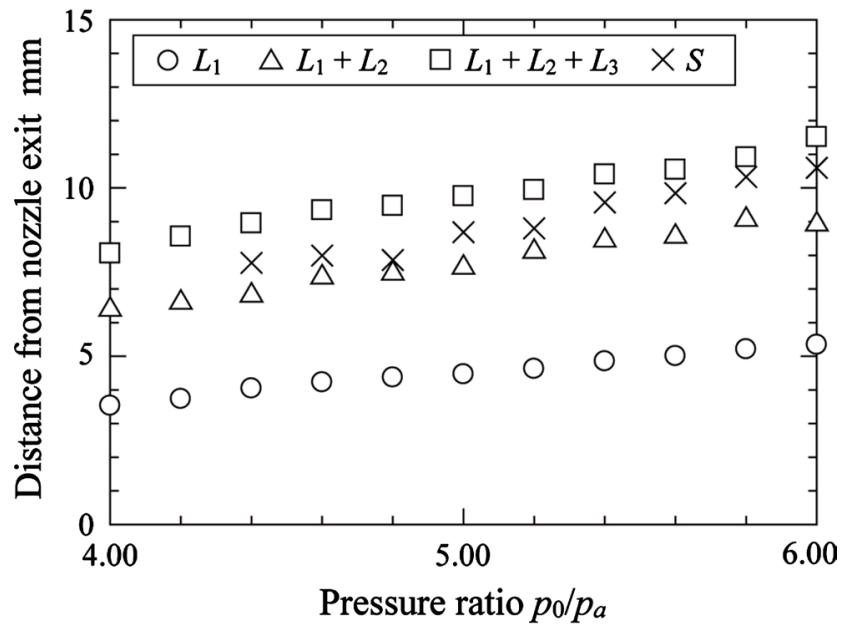

Figure 8. Cell length and location of density wave source $\left(D_{2}=12 \mathrm{~mm}\right)$.

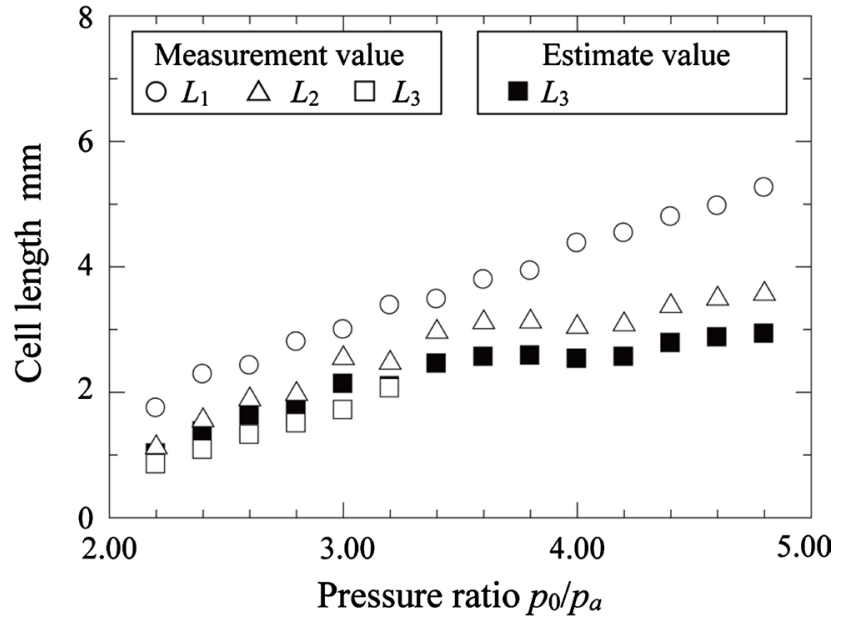

Figure 9. Cell length $\left(D_{2}=16 \mathrm{~mm}\right)$. 
As in the case of $D_{2}=12 \mathrm{~mm}$, the length of each cell increases as the pressure ratio increases. In the case of $D_{2}=16 \mathrm{~mm}$, it was difficult to measure the length of the third cell because the structure of the third cell was not stable in the range of the high pressure ratio. In this paper, the length of the third cell was estimated. Assuming that the Mach angle against the jet axis in the second cell is equal to that in the third cell, the third cell length is estimated by the calculated Mach angle in the second cell.

The solid square in the figure is the estimated length of the third cell. It can be seen that the measured third cell length and the estimated third cell length are substantially the same in the pressure ratio range of 2.20 to 3.20 . Therefore, the estimated length of the third cell is generally appropriate, and the adopted method is valid for grasping a rough tendency.

\subsection{Screech Frequency}

In order to investigate the frequency characteristics of the radiating density wave, the generation frequency was estimated using the visualized images. The result estimated from the visualized images was compared with the screech frequency of the jet noise measured by the microphone. As mentioned above, the density waves, or sound waves are emitted alternately to the left and right and the microphone is able to perceive the sound wave from only one side either on the left or the right. Therefore, in the case of estimating frequency using a visualized image, the distances $r_{L}$ and $r_{R}$ are measured from the jet axis to the farthest points corresponding to the right and left density waves as shown in Figure 10. Using the difference $\Delta r=\left|r_{L}-r_{R}\right|$, the generation frequency $f_{d}$ of the density wave was calculated from the Equation (1).

$$
f_{d}=\frac{2 \Delta r}{c_{a}}
$$

where $c_{a}$ is the ambient speed of sound. The generation frequency of the density wave from such analysis of the flow visualization is shown with a hollow mark in Figure 11. This plot is average value of 30 samples. The ordinate is frequency

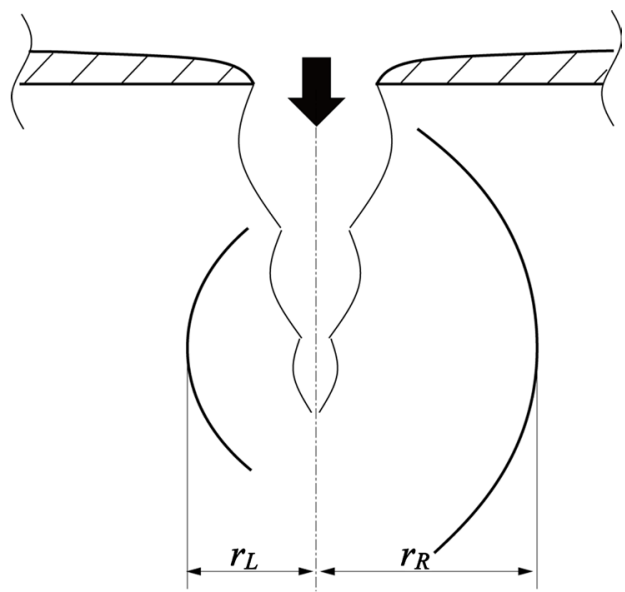

Figure 10. Measurement point of density wave. 


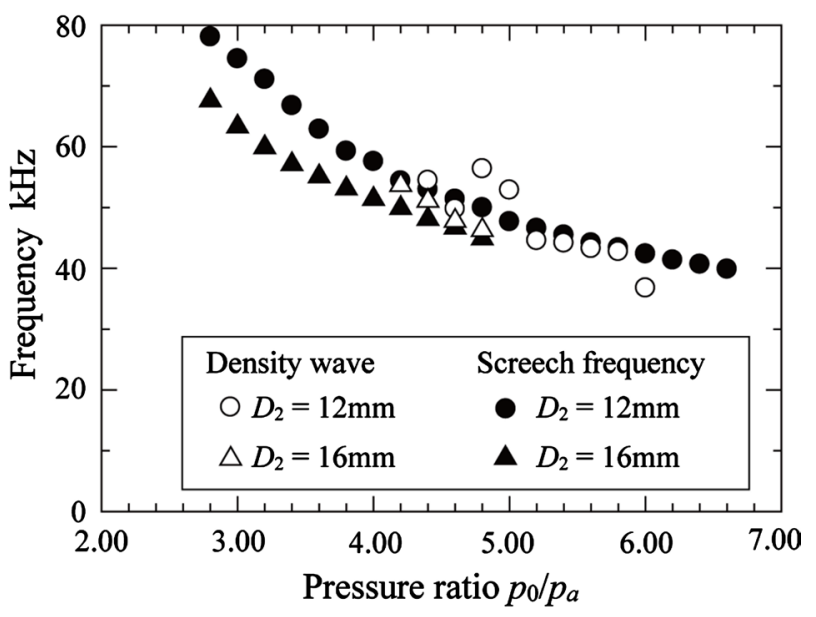

Figure 11. Generation frequency of density wave and screech frequency.

and the abscissa pressure ratio. The screech frequencies at $D_{2}=12 \mathrm{~mm}$ and 16 $\mathrm{mm}$ are also shown as a solid mark. The screech frequency tends to decrease along with the increase of the pressure ratio. The generation frequency has the same tendency as the screech frequency. The screech frequency and the generation frequency $f_{d}$ of the density waves obtained from Equation (1) are in good agreement. Therefore, it can be considered that the arc-shaped density wave generated from the radial jet is the screech emitted from the jet.

\subsection{Strouhal Number}

Strouhal number St of screech frequency calculated using Equation (2) is shown in Figure 12. The ordinate is Strouhal number, and the abscissa the pressure ratio.

$$
S t=\frac{B f}{u_{j}}
$$

here $f$ and $u_{j}$ are the fundamental frequency of the screech and the jet velocity at full expansion, respectively. Since the cell widths at the beginning and the end of the cell are different in the radial jet, a pseudo cell width $B$ is evaluated as the representative length from Equation (3) using the Tam's equation in the case of two dimensional jet [11].

$$
B=\frac{L}{2\left(M_{j}^{2}-1\right)^{\frac{1}{2}}}
$$

In Figure 12, the dashed line is the Strouhal number obtained from the empirical formula, Equation (3) derived from experiments of rectangular jet by Krothapalli et al. [7].

$$
S t=K\left(\frac{p_{0}}{p_{a}}\right)^{-1.5}
$$

where $K=0.89$. Figure 12(a) shows the result of Strouhal number calculated by substituting the second cell length $L_{2}$ for $L$. Strouhal number decreases together with the increase in pressure ratio. Strouhal numbers of the nozzle outer diameter 

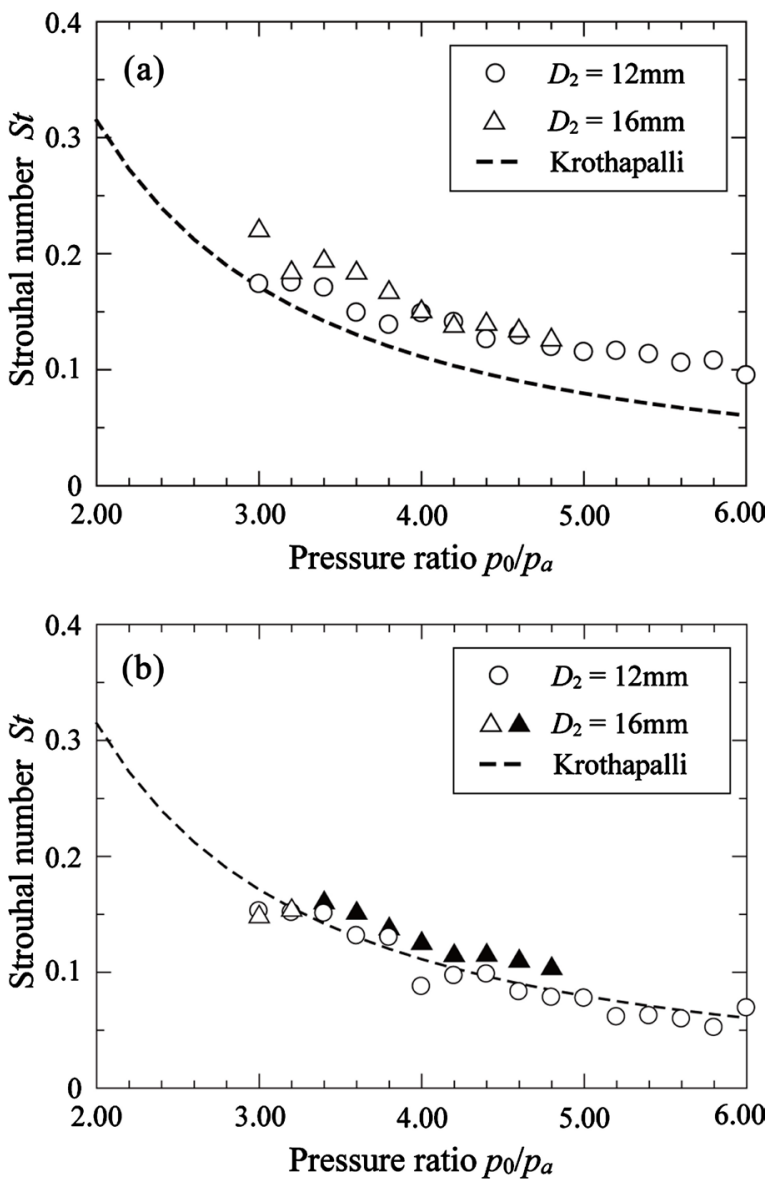

Figure 12. Strouhal number using pseudo cell width calculated from cell length. (a) $L=$ $L_{2}$; (b) $L=L_{3}$.

$D_{2}=12 \mathrm{~mm}$ and $16 \mathrm{~mm}$ are in good agreement and are close to the Krothapalli's equation. Figure 12(b) shows the calculation result when $L=L_{3}$. The empty triangles mean the values obtained by actually-measured cell length and solid ones the values based by the estimated cell length as shown in Figure 9. It can be seen that the Strouhal number of radial jet at $L=L_{3}$ quantitatively agrees well with the Krothapalli's equation. Consequently, it is considered that the screech originates in the vicinity of the third cell. According to experiments of rectangular jet by Suda et al. [9], it is reported that the third cell has sources of screech. It is interesting that the radiating positions of screech in the rectangular jet is same with the location of the cell length used in the calculation of the Strouhal number in the radial jet. This means possibly that growing-up and attenuation way of the disturbance along the jet boundary, which plays important role in deciding the screech frequency, has very similar structure in radial jet and rectangular jet.

\section{Conclusions}

The underexpanded jet spreading radially was visualized and the screech from the jet was measured. The relation was discussed between the jet structure and the screech characteristic. As a result, the following conclusions were drawn. 
1) As the radial jet goes to the downstream, the cell width decreases and the cell length also decreases accordingly. Also, the number of cells decreases as the pressure ratio increases.

2) Screech is emitted from radial jet. The result of the visualization showed that the position of the sound source exists in the third cell.

3) Using the second cell length and the Mach angle is valid for the estimation of the length of third cell.

4) A good agreement was obtained between Strouhal numbers using the pseudo cell width of the third cell and the empirical formula by Krothapalli. And the third cell length is important parameter to determine the screech frequency of the radial jet.

As concluded above, the third cell plays very important role in radiating the screech from the radial jet, while this is restricted to two types of nozzles with $D_{2}$ $=12 \mathrm{~mm}$ and $16 \mathrm{~mm}$ in our experiment. In order to clarify in detail the occurring mechanism of screech from the radial jet, many experiments should be carried out. Especially, it is necessary that the radial jets from the slit nozzle made of cylinders with smaller diameter are examined, which have stronger radial effects by the nozzle's shape. Such future works will make sound characteristics of the radial jet clear.

\section{Conflicts of Interest}

The authors declare no conflicts of interest regarding the publication of this paper.

\section{References}

[1] Carling, J.C. and Hunt, B.L. (1974) The Near Wall Jet of a Normally Impinging, Uniform, Axisymmetric, Supersonic Jet. Journal of Fluid Mechanics, 66, 159-176. https://doi.org/10.1017/S0022112074000127

[2] Fieret, J., Terry, M.J. and Ward, B.A. (1987) Overview of Flow Dynamics in Gas-Assisted Laser Cutting. SPIE High Power Lasers, 801, 243-250. https://doi.org/10.1117/12.941248

[3] Barsom, J.M. (1968) Fracture of Tempered Glass. Journal of American Ceramics Society, 51, 75-78. https://doi.org/10.1111/j.1151-2916.1968.tb11840.x

[4] Aratani, S. and Ojima, N. (1991) Effect of Shock Waves on Fracture and Quenching in Tempered Glass. Proceeding of 8th International Symposium of Shock Waves, Sendai, 21-26 July 1991, 1277-1282.

[5] Tam, C.K.W. and Tanna, H.K. (1982) Shock Associated Noise of Supersonic Jets from Convergent-Divergent Nozzles. Journal of Sound and Vibration, 81, 337-358. https://doi.org/10.1016/0022-460X(82)90244-9

[6] Norum, T.D. and Seiner, J.M. (1982) Measurements of Mean Static Pressure and Far Field Acoustics of Shock-Containing Supersonic Jets. NASA TM 84521.

[7] Krothapalli, A., Hsia, Y., Baganoff, D. and Karamcheti, K. (1986) The Role of Screech Tones in Mixing of an Underexpanded Rectangular Jet. Journal of Sound and Vibration, 106, 119-143. https://doi.org/10.1016/S0022-460X(86)80177-8

[8] Powell, A., Umeda, Y. and Ishii, R. (1992) Observation of the Oscillation Modes of 
Choked Circular Jets. Journal of the Acoustical, Society of America, 92, 2823-2836. https://doi.org/10.1121/1.404398

[9] Suda, H., Manning, T.A. and Kaji, S. (1993) Transition of Oscillation Modes of Rectangular Supersonic Jet in Screech. 15th AIAA Aeroacoustics Conference, Long Beach, 25-27 October 1993, AIAA Paper 93-4323.

https://doi.org/10.2514/6.1993-4323

[10] Tam, C.K.W., Seiner, J.M. and Yu, J.C. (1986) Proposed Relationship between Broadband Shock Associated Noise and Screech Tones. Journal of Sound and Vibration, 110, 309-321. https://doi.org/10.1016/S0022-460X(86)80212-7

[11] Tam, C.K.W. (1988) The Shock-Cell Structures and Screech Tone Frequencies of Rectangular and Non-Axisymmetric Supersonic Jets. Journal of Sound and Vibration, 121, 135-147. https://doi.org/10.1016/S0022-460X(88)80066-X

[12] Tam, C.K.W. (1992) Broadband Shock Associated Noise from Supersonic Jets Measured by a Ground Observer. AIAA Journal, 30, 2395-2401. https://doi.org/10.2514/3.11239

[13] Raman, G. (1997) Screech Tones from Rectangular Jets with Spanwise Oblique Shock-Cell Structures. Journal of Fluid Mechanics, 330, 141-168. https://doi.org/10.1017/S0022112096003801

[14] Panda, J. (1998) Shock Oscillation in Underexpanded Screeching Jets. Journal of Fluid Mechanics, 363, 173-198. https://doi.org/10.1017/S0022112098008842

[15] Suzuki, H., Endo, M. and Sakakibara, Y. (2013) A Study on Behaviour of Underexpanded Jet and Induced Vortex. International Journal of Aeroacoustics, 12, 521-538. https://doi.org/10.1260/1475-472X.12.5-6.521

[16] Hiramoto, Y., Suzuki, H., Endo, M. and Sakakibara, Y. (2019) A Study on Broad Band Noise Emitted from Underexpanded Radial Jet. Open Journal of Fluid Dynamics, 9, 72-81. https://doi.org/10.4236/ojfd.2019.91005

[17] Tam, C.K.W., Parrish, S.A. and Viswanathan, K. (2014) Harmonic of Jet Screech Tones. AIAA Journal, 52, 2471-2479. https://doi.org/10.2514/1.J052850 